\section{Effect of Cariogenic Challenge on the Degradation of Adhesive-Dentin Interfaces}

\author{
Fernanda Borguetti Manfroi ${ }^{10}$, Eduardo Miranda Ethur ${ }^{2}{ }^{(\mathbb{D}}$, Deise Caren \\ Somacal ${ }^{1(\mathbb{D})}$, Tamara Paludo ${ }^{10}$, Ana Maria Spohr ${ }^{1}$ (i)
}

'Department of Restorative Dentistry, PUC - Pontifícia Universidade Católica do Rio Grande do Sul, Porto Alegre, RS, Brazil

${ }^{2}$ Center of Technological Sciences, Industrial Chemistry, UINIVATES

- Universidade do Vale do

Taquari, Lajeado, RS, Brazil

Correspondence: Ana Maria Spohr, Avenida lpiranga, 668, 90619-900 Porto Alegre, RS, Brasil. Tel.: +55-51-3320.3538. e-mail: ana.spohr@pucrs.br

Key Words: Adhesives, bond strength, pH cycling, dentin, leakage.

\section{Introduction}

The chemical and physical characteristics and aspects concerning the oral cavity may influence the restorative materials' properties (1). Among the cited factors, the dental biofilm $\mathrm{pH}$ undergoes variations during the demineralization and remineralization process in vivo, and the physical and chemical structure of the materials may be changed by the environment (2). In environments with high cariogenic challenges, changes are present on the materials' surfaces (3), and mineral loss can occur on the tooth/restoration interface (4). These changes may negatively affect the bonding interface and produce marginal deterioration like discoloration and secondary caries, decreasing the restoration longevity (5).

The adhesive interfaces obtained in dentin have different characteristics depending on the type of adhesive system employed (6), that is, the etch-and-rinse mode (two- or three-step) or self-etch mode (one- or two-step) (7). Scothbond Bond Multi-Purpose (SBMP) is an etchand-rinse adhesive system, and Clearfil SE Bond (CSE) is a self-etch adhesive system. Both adhesive systems have been in the market for many years (8). Another adhesive system category is classified as "multi-mode" or "universal," such as Single Bond Universal (SBU). According to the manufacturers, universal adhesives can be applied using either the etch-and-rinse or the self-etch modes. However, it is important that universal adhesive systems are comparable or achieve better performance than other adhesive systems under different oral challenges.

One of the oral challenges is the alterations in the dental plaque $\mathrm{pH}$. Among the in vitro tests available, the $\mathrm{pH}$ cycling model has been successfully used to evaluate cariogenic challenge and the effectiveness of bonding in the adhesive-dentine interfaces $(4,9)$. However, the effect of $\mathrm{pH}$ cycling on the performance of adhesive-dentin interfaces is not well established.

Given the need for further analyses of the dentin bonded interface with adhesive systems under cariogenic challenges, this study evaluated the effect of $\mathrm{pH}$ cycling on microtensile bond strength ( $\mu \mathrm{TBS}$ ) and percentage of nanoleakage $(\% \mathrm{NL})$ of different adhesive systems applied to dentin. The hypotheses tested were that (1) pH cycling influences the $\mu$ TBS of the adhesive systems to dentin, (2) $\mathrm{pH}$ cycling influences the \% NL at the dentin-adhesive 
interface, and (3) there is significant difference in $\mu \mathrm{TBS}$ and \%NL among the adhesive systems.

\section{Material and Methods}

\section{Material and Specimen Preparation}

Fifty-six human third molars, extracted for therapeutic reasons, were collected from young adults aged between 17 and 30 years after approval from the Ethics Committee (55675416.7.0000.5336). The teeth were disinfected in $0.5 \%$ chloramine solution for $24 \mathrm{~h}$ and storaged in distilled water at $4^{\circ} \mathrm{C}$.

The roots were mounted in self-cured acrylic resin, and the occlusal enamel surface was removed using a watercooled, low-speed diamond saw (Extec Corp., London, UK) mounted in a laboratory-cutting machine (Labcut 1010, Extec Corp., London, UK). The superficial dentin was exposed and finished with 600-grit silicon carbide abrasive paper under running water in a polishing machine (DPU-10, Panambra, São Paulo, SP, Brazil) for $15 \mathrm{~s}$. The teeth were randomly divided into four groups $(n=14)$ according to the materials applied (Table 1).

Group 1 - SBU applied in the etch-and-rinse mode: the dentin was etched with 35\% phosphoric acid for 15 $\mathrm{s}$, followed by an air rinse and a water spray for $15 \mathrm{~s}$. The excess water was removed with cotton buds. The adhesive was applied with a microbrush and scrubbed for $20 \mathrm{~s}$, followed by gentle air-drying for $5 \mathrm{~s}$. The adhesive was light cured for $10 \mathrm{~s}$ with a light-curing unit (LED Radii-cal, SDI, Vic., Australia) with light intensity of $1.000 \mathrm{~mW} / \mathrm{cm} 2$. The light intensity was assessed by a radiometer (Model 100 Demetron, Saint Louis, MN, USA).

Group 2 - SBU applied in the self-etch mode: the

Table 1. Materials used in the study

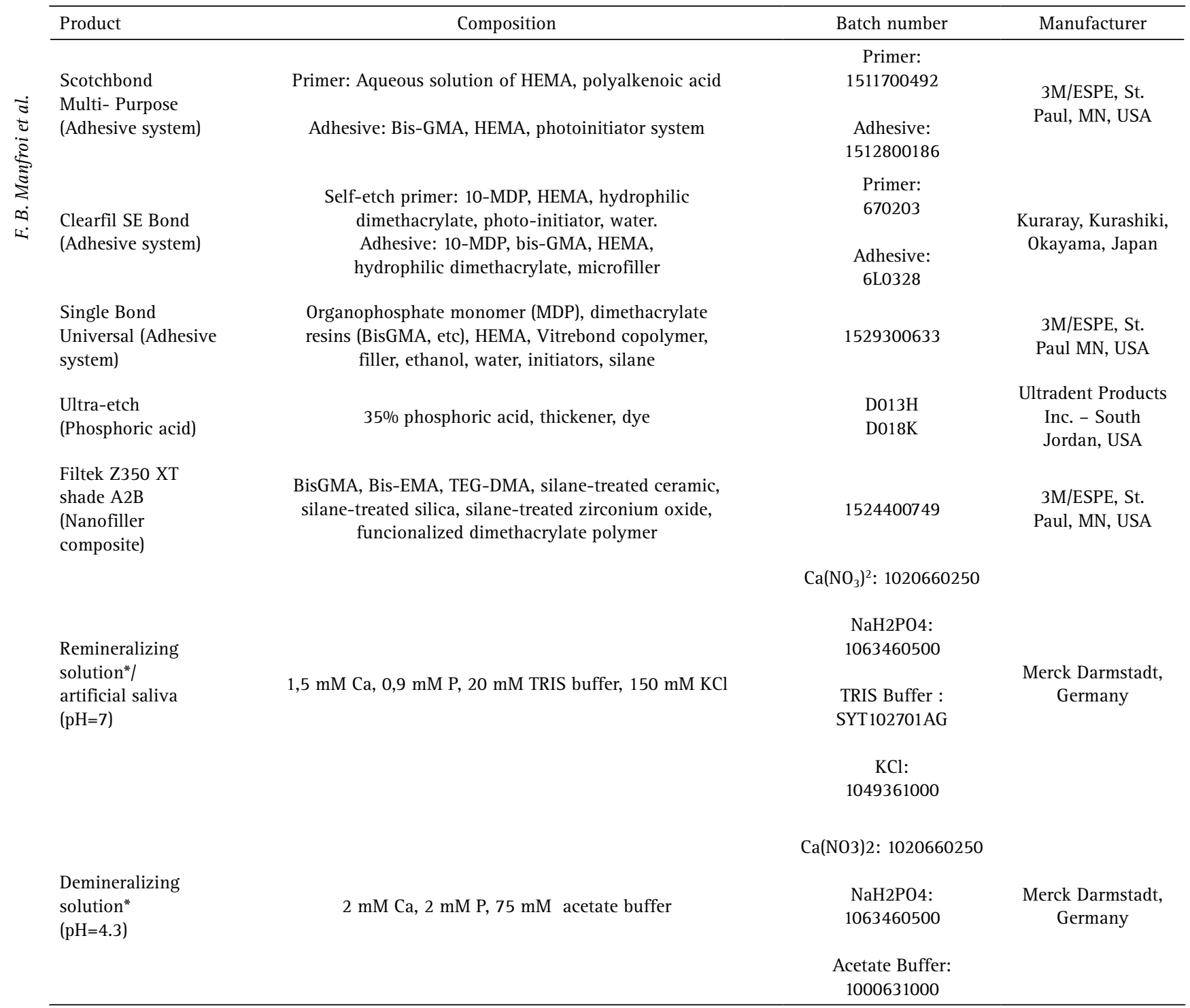


adhesive was applied to the dentin with a microbrush and scrubbed for $20 \mathrm{~s}$, followed by gentle air drying for $5 \mathrm{~s}$ and light-curing for $10 \mathrm{~s}$.

Group 3 - SBMP: the dentin was etched with 35\% phosphoric acid for $15 \mathrm{~s}$, followed by rinsing with air and a water spray for $15 \mathrm{~s}$. The excess water was removed with cotton buds. A layer of primer was applied for $15 \mathrm{~s}$, followed by gentle air drying for $5 \mathrm{~s}$. Subsequently, the bond was applied for $10 \mathrm{~s}$ with a microbrush and light cured for $10 \mathrm{~s}$.

Group 4 - CSE: the self-etching primer was applied to the dentin using a microbrush and scrubbed for $20 \mathrm{~s}$, followed by gentle air drying for $5 \mathrm{~s}$. The bond was applied using a microbrush and light cured for $10 \mathrm{~s}$.

After the adhesive systems were applied, the surface was built up using three layers of Z250 (3M, St. Paul, MN, USA) composite resin to result in a height of $6 \mathrm{~mm}$. Each layer was light cured for $40 \mathrm{~s}$. The samples were stored for $24 \mathrm{~h}$ at $37{ }^{\circ} \mathrm{C}$ in distilled water.

\section{Dentin $\mu$ TBS Test}

The number of beams was obtained through sample size calculation performed on the software Minitab 18 (Minitab, State College, PA, USA). The first adhesive system tested in the study was Single Bond Universal (etch-andrinse mode) to sound dentin, being the values considered for sample size calculation. The bond strength mean and standard deviation was $39 \mathrm{MPa} \pm 11 \mathrm{MPa}$. Using an $\alpha$ 0.05 , a power of $80 \%$ and a two-sided test, the minimum sample size was 21 beams in each group in order to detect a difference of $10 \mathrm{MPa}$ among groups.

Eight tooth/resin composite sets per group were sectioned perpendicular to the bonding surface using a water-cooled low-speed diamond saw (Extec) mounted in a laboratory-cutting machine (Labcut 1010). The samples were cut into approximately $0.90 \times 0.90 \mathrm{~mm}$ transverse sections, measured with a digital caliper (Mitutoyo Sul Americana Ltda., Suzano, SP, Brazil). Six beams from the central region of each tooth were obtained and examined with a stereomicroscope (Olympus Corp., Tokyo, Japan) at $25 \times$ magnification to analyze the adhesive area. The samples presenting defects, such as bubbles, lack of material or irregular areas, were discarded. Twenty-four beams were randomly selected and immediately submitted to a $\mu$ TBS test, and the other 24 beams were submitted to the $\mathrm{pH}$ cycling model to simulate cariogenic alteration. Pre-failures did not occur.

The composition of the demineralizing (De) and remineralizing (Re) solutions are in Table 1. The amount of solution and the number of cycles followed the protocol of Peris et al. (10). For the De solution, $6.25 \mathrm{ml}$ was used for each $\mathrm{mm} 2$ of exposed dentin; and for the Re solution, $3.125 \mathrm{ml}$ was used for each $\mathrm{mm} 2$ of exposed area. The
$\mathrm{pH}$ cycling was composed of four cycles, and each cycle consisted of immersing the beams in the De solution for $6 \mathrm{~h}$ and subsequent immersion in the Re solution for 18 $\mathrm{h}$. The beams were washed with deionized water for 1 min between immersions in the solutions. After the four cycles of De and Re solutions, the beams were submitted to the $\mu$ TBS test.

The samples were fixed with cyanoacrylate glue (Loctite, São Paulo, SP, Brazil) to a microtensile testing device. The samples were stressed at a crosshead speed of $0.5 \mathrm{~mm} / \mathrm{min}$ until failure in a universal testing machine (EMIC DL-2000, São José dos Pinhais, PR, Brazil) using a cell load of $50 \mathrm{~N}$. The $\mu$ TBS was expressed in MPa and derived by dividing the imposed force $(\mathrm{N})$ at the time of fracture by the bond area $(\mathrm{mm} 2)$.

The fractured surfaces of all samples were sputter coated with gold (Bal-Tec, Balzers, Liechtenstein) for 120 $\mathrm{s}$ at $20 \mathrm{~mA}$ and observed by scanning electron microscopy (SEM) (Inspect F50, FEl, Hillsboro, OR, USA) under $250 \mathrm{X}$ magnification, operated at $20 \mathrm{kV}$ and working distance of $14 \mathrm{~mm}$. The failures were classified as adhesive (failure between adhesive and dentin, or between adhesive and composite resin), cohesive in dentin (failure inside the dentin), cohesive in composite resin (failure in composite resin), or mixed (two or more types of failure).

\section{Nanoleakage Analysis}

After storage in water for $24 \mathrm{~h}$, six tooth/resin composite sets per group were cut in the long axis of the tooth using a water-cooled low-speed diamond saw (Extec) mounted in a laboratory-cutting machine (Labcut 1010) to obtain two slices (1 $\mathrm{mm}$ thickness) from the central region. Subsequently, two layers of nail polish were applied, leaving $1 \mathrm{~mm}$ below and $1 \mathrm{~mm}$ above the exposed adhesive interface. Half samples were subjected to the procedures for the nanoleakage after storage in water for $24 \mathrm{~h}(n=6)$, and the others after the $\mathrm{pH}$-cycling model $(\mathrm{n}=6)$.

In the sequence, the samples were immersed in a 50 wt $\%$ silver nitrate solution ( $\mathrm{pH}=4.2)$. After immersing in the tracer solution for $24 \mathrm{~h}$, the samples were rinsed with deionized water for $5 \mathrm{~min}$ and placed in a photodeveloping solution for $8 \mathrm{~h}$ under fluorescent light to reduce the diamine silver ions into metallic silver grains. The samples were then rinsed in distilled water and the nail polish was removed. The samples were immerged in $2.5 \%$ glutaraldehyde for $12 \mathrm{~h}$ in order to fix the dentin. The samples were washed with distilled water for $1 \mathrm{~min}$, followed by dehydration with rising ethanol concentrations (25\% for $15 \mathrm{~min}, 50 \%$ for $15 \mathrm{~min}, 75 \%$ for $15 \mathrm{~min}, 95 \%$ for $30 \mathrm{~min}$, and $100 \%$ for $60 \mathrm{~min}$ ). The samples were immerged in 50\% HMDS and 50\% alcohol at 100\% for 5 min (in a hood) and then placed in 100\% HMDS for 10 min (in a 
hood). The samples dried overnight in a greenhouse.

The samples were embedded in epoxi resin and polished with 400-, 600-, 800-, and 1200-grit silicone carbide abrasive papers under moisture and then polished with 6-, $3-, 1-$ and $0.25-\mu \mathrm{m}$ grit diamond pastes on a felt disk with manual pressure. Between each diamond paste, the samples were ultrasonically cleaned in distilled water for $10 \mathrm{~min}$. The samples dried for $24 \mathrm{~h}$ in a greenhouse, sputter coated with gold (Bal-Tec, Balzers, Liechtenstein) for $120 \mathrm{~s}$ at 20 $\mathrm{mA}$, and observed by SEM (Inspect F50, FEl, Hillsboro, OR, USA) in a backscattered mode under 2,000 X magnification at $20 \mathrm{kV}$ and working distance of $10-14 \mathrm{~mm}$. Three equally spaced images of the same magnification were obtained for each slice.

The 2,000x magnification photomicrographs of each region were analyzed using the ImageJ program (National Institutes of Health, Bethesda, MD, USA) to quantify the percentage of nanoleakage (\%NL). This was calculated based on the contrast and brightness of each pixel in the 2000x image generated by SEM.

\section{Statistical Analysis}

$\mu \mathrm{TBS}$ and \%NL values were submitted to the ShapiroWilk normality test. As there was normality in the values, the data were analyzed using two-way analysis of variance (adhesive system $x$ mode of storage) and post-hoc multiple comparisons using Tukey's test. $\mathrm{P} \leq 0.05$ was considered significant. The software used was SPSS v10.0 (SPSS Inc., Chicago, IL, USA).

\section{Results}

\section{Dentin $\mu T B S$}

According to two-way ANOVA, the adhesive system factor $(p=0.0001)$, the mode of storage factor $(p=0.0001)$, and the interaction between the two factors were significant $(p=0.0001)$.

At $24 \mathrm{~h}$ of storage time, no significant differences existed in the mean $\mu$ TBS among the adhesive systems $(p>0,05)$. However, after $\mathrm{pH}$ cycling, a significant difference was noted among the adhesive systems. SBU applied in the etch-and-rinse mode presented the highest mean $\mu \mathrm{TBS}$, which was not significantly different from SBMP. SBMP also did not differ significantly from CSE and SBU in the self-etch mode. For all adhesive systems, the mean $\mu$ TBS at $24 \mathrm{~h}$ of storage time was significantly higher than after the $\mathrm{pH}$ cycling (Table 2).

There was a predominance of mixed failures in all groups at $24 \mathrm{~h}$ of storage time. After the $\mathrm{pH}$ cycling, there was reduction in the number of mixed failures and the occurrence of more adhesive failures between adhesive and dentin when compared to the $24 \mathrm{~h}$ of storage time for the SBU in both modes (etch-and-rinse and self-etch) and the CSE. No group presented cohesive failure in dentin. SBMP showed no cohesive failure in composite resin (Table 2).

\section{Nanoleakage}

According to two-way ANOVA, the adhesive system factor $(p=0.0001)$, the mode of storage factor $(p=0.0001)$, and the interaction between the two factors were significant $(p=0.0001)$.

At $24 \mathrm{~h}$ of storage time, no significant differences existed in \%NL among the adhesive systems ( $p>0.05)$. However, after $\mathrm{pH}$ cycling, a significant difference was noted among the adhesive systems. SBU applied in the etch-and-rinse mode obtained the highest $\% \mathrm{NL}$, differing significantly from the other groups. SBMP obtained the second highest \%NL, differing significantly from CSE and SBU applied in the self-etch mode. The last two groups did not differ significantly from each other. The \%NL was significantly higher after $\mathrm{pH}$ cycling in comparison to 24 $\mathrm{h}$ of storage time for all adhesive systems (Table 3).

Figure 1 shows representative SEM micrographs (2000x) of the nanoleakage observed in the different groups at $24 \mathrm{~h}$ and after $\mathrm{pH}$ cycling. After $\mathrm{pH}$ cycling, higher nanoleakage was observed for SBU in the etch-and-rinse mode (e - white arrow) and SBMP ( $g$ - white arrow), and less nanoleakage occurred for SBU in the self-etch mode ( $f$ - white arrow) and for CSE (H - white arrow).

Table 2. $\mu$ TBS means (MPa) to dentin and standard deviations (SD) and mode of failure (\%) in the groups

\begin{tabular}{|c|c|c|c|c|c|c|c|c|}
\hline & $24 \mathrm{~h}$ & $\begin{array}{l}\text { Cariogenic } \\
\text { challenge }\end{array}$ & $\mathrm{A} 24 \mathrm{~h}$ & $\mathrm{CC} 24 \mathrm{~h}$ & $\mathrm{M} 24 \mathrm{~h}$ & $\mathrm{ApH}$ & $\mathrm{CCpH}$ & $\mathrm{MpH}$ \\
\hline $\begin{array}{l}\text { Single Bond } \\
\text { Universal (SBU) total-etch }\end{array}$ & $39.0 \mathrm{Aa} \pm 11.0$ & $25.0 \mathrm{Ab} \pm 5.0$ & 10 & 10 & 80 & 24 & 28 & 48 \\
\hline $\begin{array}{l}\text { Single Bond Universal (SBU) } \\
\text { self-etch }\end{array}$ & $31.0 \mathrm{Aa} \pm 13.0$ & $19.0 \mathrm{Bb} \pm 4.0$ & 5 & 5 & 90 & 51 & 4 & 45 \\
\hline Scotchbond Multi- Purpose (SBMP) & $34.0 \mathrm{Aa} \pm 14.0$ & $22.0 \mathrm{ABb} \pm 6.0$ & 25 & - & 75 & 30 & - & 70 \\
\hline Clearfil SE Bond (CSE) & $36 \mathrm{Aa} \pm 11.0$ & $21.0 \mathrm{Bb} \pm 4.0$ & 15 & 5 & 80 & 65 & 5 & 30 \\
\hline
\end{tabular}

Means followed by different capital letters in columns and different lowercase letters in rows present significant differences according Tukey's test $(\mathrm{p}<0.05)$. A24h: Adhesive, CC24h: Cohesive in composite resin; M24h: Mixed; ApH: Adhesive; CCpH Cohesive in composite resin, MpH Mixed. 


\section{Discussion}

In the present study, the SBU, SBMP, and CSE adhesive systems were used. In the immediate evaluation $(24 \mathrm{~h}$ storage in water), the adhesive systems did not present significant differences in the mean $\mu$ TBS and \%NL. However, after the $\mathrm{pH}$ cycling simulating cariogenic challenge, there was a significant decrease in the mean $\mu \mathrm{TBS}$ and a significant increase in the \%NL for all adhesive systems, and there were significant differences among the adhesive systems. Within the limitations of this study, particularly concerning dentin substrate, the results demonstrate that aesthetic restorations in which an adhesive system is used would be sensitive to $\mathrm{pH}$ changes that may occur in the oral cavity. The $\mathrm{pH}$ changes, in addition to other factors, make possible the occurrence of caries (11). Therefore, the three hypotheses of the study were accepted.

For the $\mu$ TBS methodology, the samples were submitted to cariogenic challenge in the form of beams, and in the

Table 3. Percentage of nanoleakage (\%NL) and standard deviations (SD) of the groups

\begin{tabular}{lcc}
\hline Groups & $24 \mathrm{~h}$ & $\begin{array}{c}\text { Cariogenic } \\
\text { challenge }\end{array}$ \\
\hline $\begin{array}{l}\text { Single Bond Universal } \\
\text { total-etch }\end{array}$ & $1.68 \mathrm{Aa} \pm \pm 0.29)$ & $11.27 \mathrm{Ab}( \pm 1.88)$ \\
$\begin{array}{l}\text { Single Bond Universal } \\
\text { self-etch }\end{array}$ & $1.41 \mathrm{Aa}( \pm 0.11)$ & $6.49 \mathrm{Cb}( \pm 1.14)$ \\
$\begin{array}{l}\text { Scotchbond Multi- Purpose } \\
\text { Clearfil SE Bond }\end{array}$ & $2.41 \mathrm{Aa}( \pm 0.21)$ & $8.62 \mathrm{Bb}( \pm 0.79)$ \\
\hline
\end{tabular}

Means followed by different capital letters in columns and by different lowercase letters in lines present significant differences according Tukey's test $(\mathrm{p}<0.05)$. form of slices for the nanoleakage methodology. This allowed the demineralizing and remineralizing solutions to be in contact with all sides of the adhesive interface, as well as the dentin, adhesive, and composite resin before being submitted to the tests. Possible reasons for the influence of cariogenic challenge on the mean $\mu \mathrm{TBS}$ and \%NL may be related to different factors: a) loss of dentin minerals and reduction of the resistance of this substrate and of the adhesive interface, weakening the bond between dentin and resinous materials (12); b) degradation of the organic matrix of the adhesives and weakening of the mechanical properties of these materials (13); c) enzymatic and/or hydrolytic degradation of the collagen fibers not enveloped by the resinous monomers at the bottom of hybrid layer (8).

The cariogenic challenge significantly decreased the mean $\mu$ TBS to dentin for the two application modes of the SBU. Although the mean $\mu$ TBS was significantly higher in the etch-and-rinse mode (25 MPa) in comparison with the self-etch mode (19 MPa) after cariogenic challenge, both application modes resulted in similar numerical reductions of the mean $\mu \mathrm{TBS}$, being 14 and $12 \mathrm{MPa}$ respectively. In addition, the lowest mean $\mu$ TBS in the self-etch mode (19 MPa) corresponded to the lowest \%NL (6.49\%) after cariogenic challenge. In contrast, the highest mean $\mu$ TBS in the etch-and-rinse mode (25 MPa) corresponded to the highest \%NL (11.27\%).

The lowest $\% \mathrm{NL}$ after cariogenic challenge was obtained by the SBU in the self-etch mode. Another study also demonstrated less nanoleakage for SBU applied in the self-etch mode when compared to the same adhesive in the etch-and-rinse mode (14). The present study also demonstrated that CSE, which is considered the gold standard of self-etch adhesives, did not differ significantly
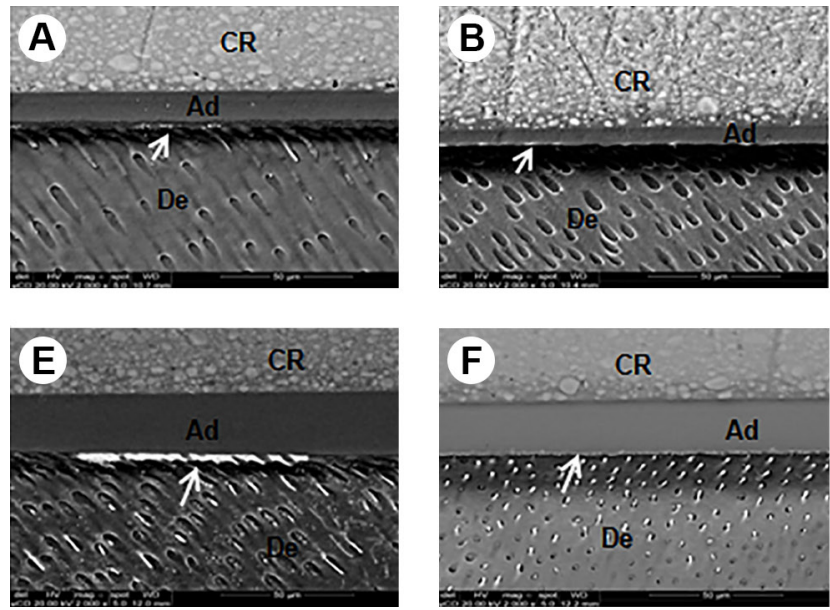
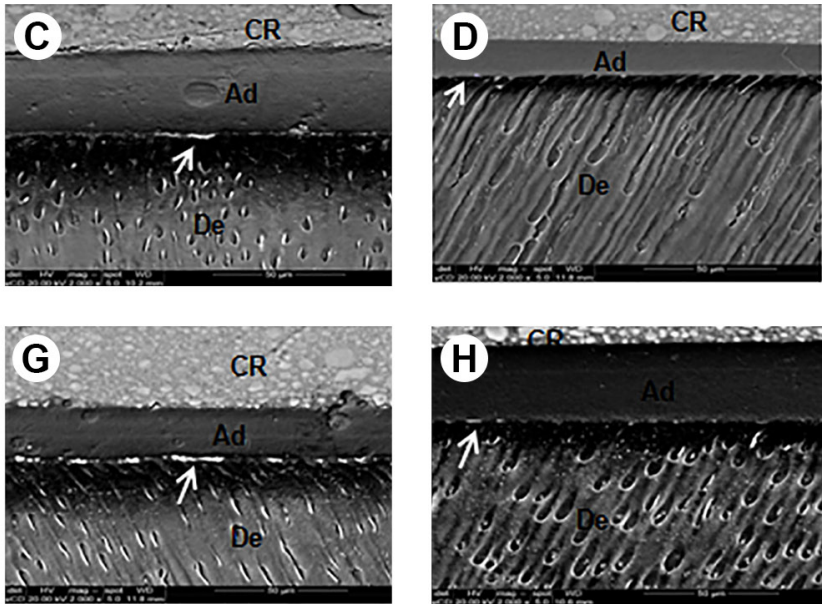

Figure 1. SEM micrographs (2000x) of the interface between dentin and the adhesive systems at $24 \mathrm{~h}(\mathrm{~A}, \mathrm{~B}, \mathrm{C}, \mathrm{D})$ and after cariogenic challenge $(\mathrm{E}, \mathrm{F}, \mathrm{G}, \mathrm{H})$. De: Dentin; Ad: adhesive; CR: Composite resin. Single Bond Universal in the etch-and-rinse mode (A,E); Single Bond Universal in the self-etch mode (B,F); Scotchbond Multi-Purpose (C,G); Clearfil SE Bond (D,H). 
from the SBU in the self-etch mode. Therefore, lower \%NL was obtained in the self-etch modes. A possible explanation may be that phosphoric acid plays a role in the difference in nanoleakage percentages noticed between etch-andrinse and self-etch modes.

In the etch-and-rinse adhesive systems, the bonding mechanism is based on the dentin etching with $35 \%$ phosphoric acid, causing total dentin demineralization and exposure of the collagen fibers, which must be enveloped by the resinous monomers to form the hybrid layer. However, in the etch-and-rinse mode, there is a greater possibility for the collagen fibers being not enveloped by the adhesive monomers, due to the incomplete infiltration of the resin monomers in the deeper layers of the demineralized dentin (15), favoring nanoleakage by the impregnation of silver particles in these spaces. It is important to emphasize that this incomplete infiltration would also expose the collagen fibers to hydrolytic and enzymatic degradation (16).

In the self-etch adhesive systems, the dentin is partially demineralized, remaining residual apatite in the collagen fibers and must be surrounded by the resinous monomers to form the hybrid layer (17). SBU applied in the self-etch mode and CSE presented mean $\mu$ TBS that did not differ significantly between them and obtained the lowest percentages of nanoleakage also without significant difference. The referred findings were obtained for the two adhesive systems, which have similarities in their compositions. Both adhesive systems incorporate 10-methacryloyloxydecyl dihydrogen phosphate monomer (10-MDP), which is able to chemically bond to the hydroxyapatite in dentin and enamel (18). In the selfetch mode, this monomer interacts with the residual hydroxyapatite that remains around the collagen fibers, enhancing the bond. A hydrolytically stable salt (MDPCa) is created by the bond of 10-MDP to calcium (19), protecting against hydrolysis (20). Hence, the presence of a hybrid layer containing fewer collagen fibers that were exposed to degradation and the presence of the MDP-Ca salt may have contributed to a more stable interface with less nanoleakage for the CSE and SBU in the self-etch mode (21).

SBU also contains polyalkenoic acid copolymer in its composition. This copolymer provides spontaneous chemical bonding to hydroxyapatite (22). The carboxyl groups, in the polyalkenoic acid copolymer, bond to hydroxyapatite by replacing phosphate ions on the substrate, creating ionic bonds to calcium (23). This is one more possibility of chemical bond of SBU to dentin.

SBMP is an etch-and-rinse adhesive system which has been used for many years. This adhesive system obtained an intermediate mean $\mu$ TBS and did not differ significantly from the other adhesive systems. The \%NL of the SBMP was lower in comparison with the SBU in the etch-andrinse mode, but higher than the adhesive systems applied in the self-etch mode. This finding evidences the tendency of lower nanoleakage for the self-etch adhesive systems.

The failure mode after $\mu$ TBS test was determined by SEM. This observation determines if the methodology applied provides bond strength values that correspond to the adhesive-dentin interface. In addition, allows analysis of the regions that are more susceptible to failures. This analysis demonstrates that the adhesive systems chosen for the present study had a strong bond to dentin since mixed failure was the most common failure mode at $24 \mathrm{~h}$ storage time. After the cariogenic challenge, there was a decrease in the mixed failures and an increase in the adhesive failures. The cariogenic challenge may have induced the weakening of the mechanical properties of the adhesive system (13), and changes at the hybrid layer (10), justifying the appearance of a greater number of interfacial failures and the decrease in the mean $\mu$ TBS.

The bond interface is an important region because the success of the restorative treatments is based on the sealing of this interface between the restorative material and the dental substrate (24). In view of the present research, cariogenic challenge may be a factor that contributes to the degradation of the bonding interface, which is evidenced by the decrease in the mean $\mu$ TBS and by the increase in the \%NL.

The present study has the limitation of using a $\mathrm{pH}$ cycling-model that does not reproduce the real cariogenic challenges that occur in the oral cavity (25). In addition, it is an in vitro study, and care must be taken to extrapolate the results to clinical reality. Clinically, much of the dentin in which the adhesive system is applied is not exposed to $\mathrm{pH}$ changes due to cavity geometry and external enamel protection. However, in Class II cavities with cervical margins in the dentin and in Class $\mathrm{V}$ cavities with cervical margins in the dentin, it is estimated that these interfaces would be sensitive to $\mathrm{pH}$ changes.

Considering the limitations of this study, it was possible to conclude that the $\mathrm{pH}$ cycling decreased the bond strength and increased the nanoleakage at the adhesive-dentin interface for all adhesive systems evaluated. However, SBU, applied in the self-etch mode, and CSE allowed lower nanoleakage after $\mathrm{pH}$ cycling in comparison with SBU, applied in the etch-and-rinse mode, and SBMP.

\section{Resumo}

0 objetivo foi avaliar, in vitro, a influência da ciclagem de $\mathrm{pH}$ na resistência de união à microtração $(R U \mu T)$ e na porcentagem de nanoinfiltração $(\% \mathrm{NI})$ na interface dentina-adesivo. Superfícies planas em dentina foram obtidas em 56 terceiros molares. Os dentes foram aleatoriamente divididos em quatro grupos $(n=14)$ : $\mathrm{G} 1$ - Single Bond Universal (condicionamento ácido prévio); G2- Single Bond Universal (autocondicionante); G3- 
Scotchbond Multi-Purpose; G4- Clearfil SE Bond. Bloco de resina composta foi construido sobre o adesivo. Oito conjuntos dente/resina foram cortados paralelamente ao longo eixo do dente para obter 48 palitos $(0,8 \mathrm{~mm} 2)$ para cada grupo. Metade dos palitos foi submetida a quatro ciclos de ciclagem de $\mathrm{pH}$ (solução desmineralizadora por $6 \mathrm{~h}$ e solução remineralizadora por $18 \mathrm{~h}$ ). As amostras foram submetidas ao teste de RU $\mu \mathrm{T}$ em máquina de ensaio universal. Seis conjuntos dente/ resina foram cortados paralelamente ao longo eixo para obter três fatias da região central ( $1,0 \mathrm{~mm}$ de espessura). Metade das fatias foi submetida à ciclagem de $\mathrm{pH}$. A metodologia de nanoinfitração foi aplicada para obter a \%NI nas interfaces. De acordo com ANOVA de duas vias, interação entre os fatores (adesivo $x$ armazenamento) foi significativa $(p=0.0001)$ para for RU $\mu \mathrm{T}$ e \%NI. Após ciclagem de $\mathrm{pH}$, houve redução significativa na $\mathrm{RU} \mu \mathrm{T}$ e aumento significativo na \%NI para todos adesivos. Os adesivos aplicados na técnica autocondicionante obtiveram menor \%NI, diferindo significativamente dos adesivos com condicionamento ácido prévio. Concluiu-se que a ciclagem de $\mathrm{pH}$ influenciou negativamente a RU $\mu \mathrm{T}$ e a \%NI para todos adesivos. Contudo, adesivos autocondicionantes permitiram menor \%NI.

\section{Acknowledgements}

The authors thank Professor Sérgio Kato for the statistical analysis. This study was financed in part by the Coordenação de Aperfeiçoamento de Pessoal de Nivel Superior - Brasil (CAPES) - Finance Code 001.

\section{References}

1. Krüger J, Maletz R, Ottl P, Warkentin M. In vitro aging behavior of dental composites considering the influence of filler content, storage media and incubation time. PLoS One 2018;13:e0195160.

2. Nedeljkovic I, De Munck J, Ungureanu AA, Slomka V, Bartic $C$, Vananroye $A$, et al. Biofilm-induced changes to the composite surface. J Dent 2017;63:36-43.

3. Silva KG, Pedrini $D$, Delbem ACB, M Cannon. Effect of $\mathrm{pH}$ variations in a cycling model on the properties of restorative materials. Oper Dent 2007;32:328-335.

4. Maske $\Pi$, Isolan $C P$, van de Sande $F H$, Peixoto $A C$, Faria-E-Silva $A L$, Cenci MS, et al. A biofilm cariogenic challenge model for dentin demineralization and dentin bonding analysis. Clin Oral Investig 2015;19:1047-1053.

5. Manhart J, Chen H, Hamm G, Hickel R. Buonocore Memorial Lecture. Review of the clinical survival of direct and indirect restorations in posterior teeth of the permanent dentition. Oper Dent 2004;29:481508.

6. Marghalani HY, Bakhsh T, Sadr A, Tagami J. Ultramorphological assessment of dentin-resin interface after use of simplified adhesives. Oper Dent 2015;40:e28-39.

7. Sofan E, Sofan A, Palaia G, Tenore G, Romeo U, Migliau G. Classification review of dental adhesive systems: from the IV generation to the universal type. Ann Stomatol 2017;8:1-17.

8. Hashimoto M, Fujita $S$, Nagano F, Ohno H, Endo K. Ten-years degradation of resin-dentin bonds. Eur J Oral Sci 2010;118:404-410.

9. Deng $D$, Yang $H$, Guo J, Chen $X$, Zhang W, Huang C. Effects of different artificial ageing methods on the degradation of adhesive-dentine interfaces. J Dent 2014:42:1577-1585.

10. Peris AR, Mitsui FH, Lobo MM, Bedran-russo AK, Marchi GM. Adhesive system and secondary caries formation: Assessment of dentin bond strength, caries lesions depth and fluoride release. Dent Mater 2007;23:308-316.

11. Zaura $\mathrm{E}$, ten Cate JM. Towards understanding oral health. Caries Res 2015;49:55-61.

12. Nakajima $M$, Okuda $M$, Ogata $M$, Pereira PN, Tagami J, Pashley DH. The durability of a fluoride-releasing resin adhesive system to dentin. Oper Dent 2003;28:186-192.

13. Pedrosa VO, Flório FM, Turssi CP, Amaral FL, Basting RT, França FM. Influence of $\mathrm{pH}$ cycling on the microtensile bond strength of selfetching adhesives containing MDPB and fluoride to dentin and microhardness of enamel and dentin adjacent to restorations. J Adhes Dent 2012;14:525-534.

14. Marchesi G, Frassetto $A$, Mazzoni $A$, Apolonio $F$, Diolosà $M$, Cadenaro $M$, et al. Adhesive performance of a multi-mode adhesive system: 1-year in vitro study. J Dent 2014;42:603-612.

15. Van Meerbeek Al, Feilzer AJ. Four-year water degradation of a total-etch and two self-etching adhesives bonded to dentin. J Dent 2008;36:611-617.

16. Hashimoto M, Tay FR, Ohno H, Sano H, Kaga M, Yiu C, et al. SEM and TEM analysis of water degradation of human dentinal collagen. J Biomed Mater Res B Appl Biomater 2003;66:287-298.

17. Van Meerbeek B, Yoshihara $K$, Yoshida $Y$, Mine A, De Munck J, Van Landuyt KL. State of the art of self-etch adhesives. Dent Mat 2011;27:17-28

18. Yoshida $Y$, Nagakane $K$, Fukuda R, Nakayama $Y$, Okazaki M, Shintani $\mathrm{H}$, et al. Comparative study on adhesive performance of functional monomers. J Dent Res 2004;83:454-458.

19. Fukegawa D, Hayakawa S, Yoshida Y, Suzuki K, Osaka A, Van Meerbeek B. Chemical interaction of phosphoric acid ester with hydroxyapatite. Dent Res 2006;85:941-944.

20. Peumans $M$, De Munck J, Van Landuyt KL, Poitevin A, Lambrechts $P$, Van Meerbeek B. Eight-year clinical evaluation of a 2-step selfetch adhesive with and without selective enamel etching. Dent Mat 2010;26:1176-1184.

21. Oliveira $Y$, Yoshihara $K$, Nagaoka N, Hayakawa $S$, Torii $Y$, Ogawa T, et al. Self-assembled nano-layering at the adhesive interface. J Dent Res 2012;91:376-381.

22. Mitra SB, Lee CY, Bui HT, Tantbirojn D, Rusin RP. Long-term adhesion and mechanism of bonding of a paste-liquid resin-modified glassionomer. Dent Mater 2009;25:459-466.

23. Lin A, Mclntyre NS, Davidson RD. Studies on the adhesion of glassionomer cements to dentin. J Dent Res 1992;71:1836-1841.

24. Fernández EM, Martin JA, Angel PA, Mjör IA, Gordan W, Moncada GA. Survival rate of sealed, refurbished and repaired defective restorations: 4-year follow-up. Braz Dent J 2011;22:134-139.

25. Stookey GK, Featherstone JD, Rapozo-Hilo M, Schemehorn BR, Williams RA, Baker RA, et al. The Featherstone laboratory pH cycling model: a prospective, multi-site validation exercise. Am J Dent 2011;24:322-328.

Received April 26, 2019

Accepted August 21, 2019 